\title{
Performance of Children with Mental Retardation with and without Down's Syndrome on Standardized Walking Obstacle Course
}

\author{
Roosha Parikh, Priya Kulkarni, Sherin Abraham, Keerthi Rao, \\ Subhash Khatri \\ (Pravara Institute of Medical Sciences, College of Physiotherapy, Loni, India)
}

\begin{abstract}
:
Objective: To compare the performance of children with mental retardation with and without Down's syndrome on Standardised Walking Obstacle Course.

Method: A prospective comparative study consisted of 30 participants between the age group of 6-14 years. These participants were divided into 2 groups Mentally retarded with Down's syndrome and Mentally retarded without Down's syndrome. Standardised Walking Obstacle Course Test (SWOC) is used to measure stability and speed during gait in terms of time, number of steps, number of stumbles and number of steps off the path for each participant Paired, Unpaired t test and ANOVA were used for data analysis.

Results: The time taken and the number of steps off the path was significantly more $(p<0.01)$ in children with Down's syndrome as compared to children without Down's syndrome. The number of steps and the number of stumbles was also more $(p<0.01)$ in children with Down's syndrome as compared to children without Down's syndrome.

Conclusion: Overall the quality of functional ambulation is decreased in children with Down's syndrome as compared to those with Mental retardation in time, number of steps, stumbles and steps off the path.
\end{abstract}

Keywords: Down's syndrome, Mental retardation, Standardised Walking Obstacle Course

\section{Introduction}

Mental Retardation (MR) is a disability characterized by significant limitations in both intellectual functioning and adaptive behaviour expressed in conceptual, social and adaptive skills .According to DSM IVthe essential feature of mental retardation is significantly below average general intellectual functioning, accompanied by significant limitations in adaptive functioning in at least 2 of the following applicable adaptive skills areas such as communication, self-care, home living, social/interpersonal skills, use of community resources, self direction, health and safety, functional academic skills, leisure and work. ${ }^{[1]}$ These individuals find difficulty in activities of daily living and functioning in society as the ability to learn and adapt to the changing environment is limited. As compared to other groups with disabilities these individuals have more functional limitations in adaptive behavior and motor function ${ }^{[2]}$ Due to their intellectual disability the time taken to learn motor skills is prolonged. For children with MR, fitness and overall functioning is lower as they are not active during the course of the school day and have limited opportunities to participate in the physical activities available to their peers. ${ }^{[2]}$

MR can be categorized as syndromic, if associated with dysmorphic features, or nonsyndromic, if not associated with dysmorphisms or malformations. ${ }^{[3]}$ The commonest associated chromosomal abnormality is trisomy 21, or Down syndrome (DS). Down's Syndrome is a chromosomal disorder resulting in 47 chromosomes instead of 46, hence commonly called as Trisomy $21 .{ }^{[4-8]}$ It is the most common genetic form of mental retardation. ${ }^{[4,5,9]}$ The syndrome has several clinical symptoms including orthopaedic, cardiovascular, neurological, cognitive, hormonal and visual perceptual impairments. ${ }^{[10-12]}$ Along with developmental delay these children have hypotonicity, hypermobility of joints or ligamentous laxity, light to moderate obesity, an underdeveloped respiratory and cardiovascular system and short stature which in turn lead to decrease in functional ambulation. ${ }^{[5,7]}$ The rate of motor development is comparatively less as compared to non down's syndrome. Literature suggests that these individuals have reduced peak and sub maximal exercise capacity along with reduced muscle strength. The low level of physical fitness limits these individuals in performing the functional tasks of daily living. ${ }^{13]}$ Walking which is a fundamental motor skill facilitates the child to interact with the environment and in turn helps in developing motor, social and cognitive skills. ${ }^{[14,15]}$ But in these children due to their delayed milestones as well as their intellectual disability environmental exposure is reduced which hampers this fundamental skill. Hence there is a necessity to asses functional ambulation in these children in particular. 
Function and functional outcomes are best defined in relation to the environment in which they occur and participation or disability is best measured in relation to daily activities within social role. ${ }^{[16]}$ ShumwayCook et al suggested that there are various physical features that influence physical performances in the environment such as the distance and the affects of surrounding (such as illumination), physical load (such as items carried), topography (such as obstacles), and the need to make postural transitions. ${ }^{[16,18]}$ Standardized measures of the influence of these environmental variables will help to focus interventions, will make it easier to determine progress, and augment the likelihood of optimal outcomes. ${ }^{[16]}$ Gait, locomotion, and balance should be evaluated at multiple levels as these data help informing clinical decision making. In the development of a standardized test with more environmental dimensions, such as an obstacle course, an analysis of the task or tasks performed within an environment is critical ${ }^{[16]}$ The Standardized Walking Obstacle Course (SWOC) is a test that allows interaction of a child with environmental demands and obstructions while examining differences in functional ambulation performances. ${ }^{[16,22]}$ The purpose of the Standardized Walking Obstacle Course (SWOC) is to determine ambulation capacity by measuring stability and speed during gait under different circumstances in a safe, reproducible, and efficient way. ${ }^{[16,17]}$ The measures within the SWOC (time, number of steps, and observations of stability) are standard measures used in clinical practice for all patient populations. ${ }^{[16,23]}$

Recent trend in special education has highlighted and strengthened the importance of physical activity.

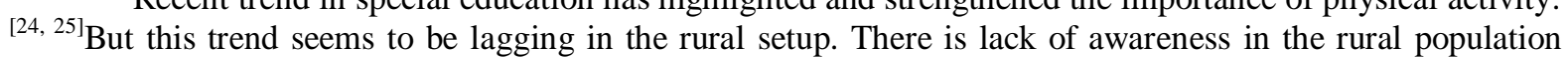
about the need for the physical therapy in these children. An appropriate physical therapy intervention if included in the school based curriculum would definitely enhance these children's physical functioning.Before chalking out the intervention it is necessary to quantify the quality of functional ambulation in these children. As discussed earlier Standardized Walking Obstacle Course (SWOC) is a reliable measure to assess the same. This study is performed to assess the quality of functional ambulation in children with mental retardation with and without Down's syndrome importance of rural population.

\section{Materials and methods:}

Children who were mentally retarded with and without Down's syndrome were recruited from Dr. Devendra Ohara Matimand Vidyalaya, a special school in Sangamner taluka,Ahmednagar district in Maharashtra for the study. The study design selected for the study was prospective comparative study. The selection criteria included children between the age group of 6-14 years with mild to moderate mental retardation(Vineland Social Maturity Scale, Binet Kamat Scale for Intelligence) with and without Down's syndrome. Additional criteria included was that the children should be ambulatory and should follow the commands. Children who had any congenital cardiac anomalies, visual or hearing deficits or any surgical interventions in the last 6months were excluded from the study. A total of 30 participants were selected by convenient sampling for the study and were divided into two groups. One group consisted of 15 participants with Down's syndrome and the other consisted of 15 participants without Down's syndrome. Standardised Walking Obstacle Course (SWOC) was used to assess the functional ambulation capacity. ${ }^{[16]}$ The SWOC is a designated walking path $39.5 \mathrm{ft}$ in length, 36 inch width, and includes $30^{\circ}, 70^{\circ}$, and $90^{\circ}$ turns. Children have to step over, on or around the obstacles placed along the path like crutch, brightly colored shag rugs, and standardheight kitchen garbage can. It is used to measure stability and speed during gait in terms of time, number of steps, number of stumbles and number of steps off the path. It was assessed under three conditions such as walk with arms free, walk with tray and walk with sunglasses.

The examiner physically performed each task before the testing of the participants for their better understanding. For each of the task the children were given a trial which would help them to differentiate between the tasks. During the performance of each task there was one examiner behind the child to ensure safety and to record the time, the other examiner walking alongside the child calculated the other parameters: Number of steps, stumbles (loss of balance or contact with any obstacle), number of steps off the path and the third examiner recorded these readings. The total time required for testing of each participant was around 1520mins. 


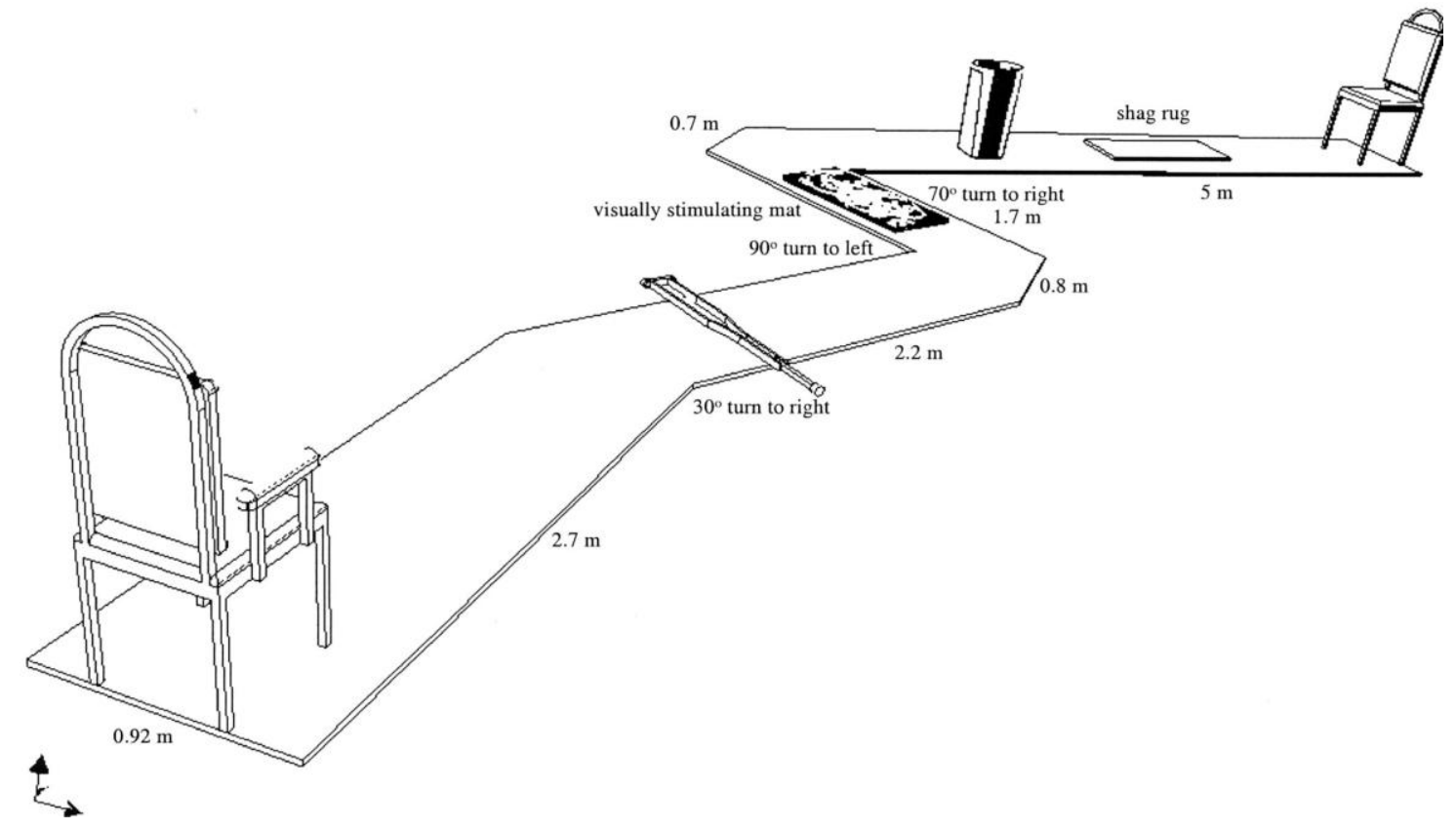

Table Number1:Mean and standard deviation of SWOC conditions

\begin{tabular}{|c|c|c|c|c|c|c|}
\hline \multirow[t]{2}{*}{$\begin{array}{l}\text { OUTCOME } \\
\text { MEASURES }\end{array}$} & \multicolumn{3}{|c|}{$\begin{array}{l}\text { MR WITHOUT DS } \\
\text { MEAN(SD) }\end{array}$} & \multicolumn{3}{|c|}{$\begin{array}{l}\text { MR WITH DS } \\
\text { MEAN(SD) }\end{array}$} \\
\hline & $\begin{array}{l}\text { ARMS FREE } \\
\text { (A) }\end{array}$ & $\begin{array}{l}\text { WITH } \\
\text { TRAY } \\
\text { (WT) }\end{array}$ & $\begin{array}{l}\text { WITH } \\
\text { GLASS } \\
\text { (WG) }\end{array}$ & $\begin{array}{l}\text { ARMS } \\
\text { FREE } \\
\text { (A) }\end{array}$ & $\begin{array}{l}\text { WITH } \\
\text { TRAY } \\
\text { (WT) }\end{array}$ & $\begin{array}{l}\text { WITH } \\
\text { GLASS } \\
\text { (WG) }\end{array}$ \\
\hline TIME & $14.37(4.01)$ & $\begin{array}{l}16.47(4.61 \\
5)\end{array}$ & $\begin{array}{l}15.44(3.36 \\
5)\end{array}$ & $\begin{array}{l}24.76(7.88 \\
5)\end{array}$ & $\begin{array}{l}26.90(5.83 \\
8)\end{array}$ & $\begin{array}{l}24.46(6.8 \\
15)\end{array}$ \\
\hline STEPS & $18.46(4.712)$ & $\begin{array}{l}18.93(4.52 \\
7)\end{array}$ & $\begin{array}{l}17.66(4.51 \\
5)\end{array}$ & $\begin{array}{l}27.86(3.44 \\
1)\end{array}$ & $\begin{array}{l}29.06(3.73 \\
1)\end{array}$ & $\begin{array}{l}27.26(3.1 \\
27)\end{array}$ \\
\hline STUMBLES & $0.266(0.4577)$ & $\begin{array}{l}0.066(0.25 \\
8)\end{array}$ & $\begin{array}{l}0.266(0.45 \\
7)\end{array}$ & $\begin{array}{l}0.6(0.6235 \\
)\end{array}$ & $\begin{array}{l}0.266(0.45 \\
17)\end{array}$ & $\begin{array}{l}0.666(0.4 \\
88)\end{array}$ \\
\hline $\begin{array}{l}\text { STEPS OFF } \\
\text { THE PATH }\end{array}$ & $0.466(0.743)$ & $\begin{array}{l}0.066(0.58 \\
2)\end{array}$ & $\begin{array}{l}0.33(0.723 \\
)\end{array}$ & $\begin{array}{l}1.533(1.35 \\
6)\end{array}$ & $1.2(1.207)$ & $\begin{array}{l}1.266(1.3 \\
87)\end{array}$ \\
\hline
\end{tabular}

Abbreviations: A-Arms free walking; WG- walking with glasses; WT- walking with tray.

\section{Results:}

Twelve outcome measures by SWOC conditions are presented in Table 1 for the whole sample. These outcome measures are time, number of steps, number of steps off, and stumbles under A, WT, and W G. The results showed that children with DS took more time to complete each task as compared to children without DS. The total number of steps, stumbles and steps off the path were obtained to be more in children with DS as compared to children without DS. The time taken and the total number of steps while walking by holding a tray was more compared to the other two tasks for children in both groups.

Data analysis to find out the significance within the group was done by paired ' $\mathrm{t}$ ' test while between the two groups was done by unpaired ' $t$ 'test and between the conditions was done by ANOVA. The results of the study suggested that there is a significant difference $(\mathrm{p}<0.001)$ in the ambulation quality in DS as compared to that in MR. In each task a highly significant result was obtained when comparing MR and DS. The total time taken by the children with DS to complete each task was highly significantly $(\mathrm{p}<0.01)$ as compared to children without DS. There is a significant $(\mathrm{p}<0.001)$ difference in the number of steps taken for each task, it is more in children with DS. It was seen that while wearing sunglasses there was a significant $(\mathrm{p}=0.0281)$ difference seen in the children with DS as compared to walking with arms free and walking with a tray which did not show much of significance. The number of steps off the path showed a highly significant difference $(p<0.01)$ in children with DS when walking with a tray as compared to the other two tasks in children without DS.

The total time, number of steps and stumbles showed a significant difference in children with DS while steps off the path did not have significant difference in DS children .The total time and number of steps had a significant difference in children without DS but there was no significant difference seen in number of stumbles and steps off the path in these children. 


\section{Discussion:}

This study was performed to compare the quality of functional ambulation in mentally retarded (MR) children with and without DS. The ambulation capacity was assessed using Standardized Walking Obstacle Course (SWOC) in both the groups. When comparing children with mental retardation with Down's syndrome (DS) to those without DS, it is found that there is more limitation in functional activities in children with DS. Children with DS took about 39\% more time than those with MR. The children with DS took shorter steps and stopped in front of every obstacle taking time to assess and adjust to the obstacle. This could be best explained by Virji Babul in his study who concluded that the children with DS were not able to make anticipatory adjustments and children adapted to the normal gait pattern of unobstructed condition. ${ }^{[17]}$ Thus it is difficult for them to use visual information about the obstacle and had to wait until they reached the obstacle to extract relevant information to modulate the motor output.

The children with DS took $34 \%$ more steps. It is mostly because there is a difference in the step length in both DS and MR. It is seen that children with DS have shorter stride length. ${ }^{[17]}$ It may be seen because of the decrease in exposure to an obstructed environment, and also due to delay in visual and perceptual development. In children with MR less number of stumbles was seen. Children with DS were observed to have minimal toe clearance which increases the possibility of stumbling and hitting obstacles. Children with DS were seen to have $56 \%$ more stumbles than those with MR especially when walking with sunglasses. It was difficult for them to adapt to the dim lit environment. In the other two tasks the difference was not that significant. The steps off the path were $69 \%$ more in children with DS than those with MR. Similar results were found by K. Kott et al in their study. ${ }^{[19]}$ In each of the tasks, the time taken and steps off the path were $5 \%$ more and stumbles were significantly less, when children were walking holding a tray in both groups. This was seen mostly because children with DS show visual and cognitive difficulties, they are used to walking in an unobstructed path so it may be hard for them to adapt to a constricted and angled path.

With this study results we can show the necessity of various interventions that can be given to DS children to improve their perceptual functioning in areas of motor functioning, toe clearance, step length strength and endurance which in turn helps in improving their gross motor skills. Interventions can also be planned out and focussed upon their functional limitations in both children with mental retardation with Down's syndrome and in children with mental retardation without Down's syndrome thus, improving their functional ambulation capacity and quality of life in the rural set up.

\section{Conclusion:}

While assessing with Standardized Walking Obstacle Course, it was found that the quality of functional ambulation is decreased in children with Down's syndrome as compared to those with Mental retardation in time, number of steps, stumbles and steps off path.

\section{Acknowledgements:}

The authors sincerely acknowledge Sharon L. Held PT, DPT, MS, PCS and Karen M. Kott, PT, PhD for guiding the use of SWOC. The authors would like to also thank the management committee of Dr. Devendra Ohara Matimand Vidyalaya for letting their students to participate in the study.

The authors would like to acknowledge Old Dominion University and DaemenCollege for allowing using SWOC in the present study. The authors would like to sincerely thank College of Physiotherapy, Pravara Institute of Medical Sciences for giving an opportunity to conduct the study and for the continuous support and guidance.

\section{Contribution:}

RP initiated and designed the study, acquisition and interpreted the data; PK contributed to the conception, design of the study, collection and interpretation of the data;SA contributed to the collection of the data and drafted the manuscript;KR supervised and revised the final manuscript;SK supervised and supported the study.

\section{Conflict of Interest:None Role of Fundingresource:None}

\section{References:}

[1]. Tecklin Jan S Pediatric Physical Therapy, Fourth edition Lippincott Williams \& Wilkins, Philadelphia chap. 10, pg 378;2008

[2]. Kubilay NS, Yildırım Y, Kara B, HarutoğluAkdurH..(2011) "Effect of balance training and posture exercises on functional level in mental retardation.’'Fizyoter Rehabil.;22(2):55-64

[3]. http://emedicine.medscape.com/article/1180709-overview (accessed on 11/2/2013)

[4]. http://www.thecochranelibrary.com (Accessed on 11/12/2011) 
[5]. Ghai O P, Ghai Essential Pediatrics, Fifth edition,Mehata publishers New Delhi chap. 22, pg 475-487;2001

[6]. www.childsplayphysio.com.au/ (Accessed on 1/8/2012)

[7]. Barbara H Connolly BC and Majorie H Woollacott MW, (1986) "Performance of retarded children, with and without Down's syndrome, on the Bruininks Oseretsky Test of Motor Proficiency”. Physical Ther;66:344-348

[8]. www.downdevelopment.nl/afb/boek_UK.pdf (Accessed on 1/7/2012)

[9]. J. R. Korenberg, X.-N. Chen, R. Schipper, Z. Sun, R. Gonsky, S. Gerwehr, N. Carpenter (1994), "Down Syndrome Phenotypes:The consequences of chromosomal imbalance", Proc. Natt. Acad. Sci. USA; 91: 4997-5001.

[10]. Maria Hernandez-Reifa, Tiffany Fielda, Shay Largiea, Dana Moraa, Joan Bornsteinb and Ronnie Waldmanb(2006) ,"Children with Down syndrome improved in motor functioning and muscle tone following massage therapy" Early Child Development and Care; $176(3 \& 4): 395-410$

[11]. Pitetti KH, Climstein M, Mays MJ, Barrett PJ(1992), "lsokinetic arm and leg strength of adults with Down syndrome: A comparative study," Archives of Physical Medicine and Rehabilitation; 73(9):847 -850.

[12]. Nora Sheilds, Nicholas F. Taylor ,Karen J Dodd(2008), "Effects of community based progressive resistance training program on muscle performance and physical function in Down's syndrome”. Arch. Phys. Med. Rehabil; 89(7):1215-20.

[13]. Goncalo V Mendonca, Fernando D Pereira, and Bo Fernhall(2010), "Reduced exercise capacity in persons with Down syndrome: cause, effect, and management" TherClin Risk Manag. ; 6: 601-610. (Published online 2010 December 8.)

[14]. Jianhua Wu, Julia Looper, Beverly D Ulrich, Dale A Ulrich , Rosa M Angulo-Barroso (2007)“ Exploring effects of different treadmill interventions on walking onset and gait patterns in infants with Down syndrome" Developmental Medicine \& Child Neurology , 49(11): 839-945

[15]. Bax M. (1991) Walking. Dev Med Child Neurol33: 471-472.

[16]. Sharon L Held, Karen M Kott and Brenda L Young(2006) "Standardized Walking Obstacle Course (SWOC): Reliability and Validity of a New Functional Measurement Tool for Children" Journal of Pediatric Physical therapy ; 18:23-30

[17]. Taylor MJ, Gunther J.(1998) "Standardized walking obstacle course: Preliminaryreliability and validity of a functional measurement tool." J Rehabil Outcomes Meas. ;2:15-25

[18]. Shumway-Cook A, Patla AE, Stewart A,(2002) et al. "Environmental demands associated with community mobility in older adults with and without mobility disabilities" PhysTher. ;82:670-681.

[19]. K. Kott"The performance of children on the Standardized walking obstacle course." Journal of Pediatric Physical therapy2005; 17(1):101.

[20]. Virji-Babul N, Brown M., "Stepping over obstacles: anticipatory modifications in children with and without Down syndrome," Experimental Brain Research. 2004; 159:487-490.

[21]. Latash ML. "Motor coordination in Down syndrome: The role of adaptive changes." In: Weeks DJ, Chua R, Elliott D, editors. Perceptual-Motor Behavior in Down Syndrome. Human Kinetics: Champaign, IL;2000. p.199-223

[22]. K M. Kott,S L. Held, Elizabeth Francis Giles;Mary Rose Franjoine (2011), "The predictors of standardized walking obstacle course as outcome measures in children with and without developmental disabilities." Journal of Pediatric Physical Therapy ; 23:365-373.

[23]. Shumway-Cook A, Woollacott MH(1985) Dynamics of Postural Control in the Child with Down Syndrome PhysTher 65:1315-1322

[24]. Fabian E.S., R.W. Lent, and S.P. Willis(1998) "Predicting work transition outcomes for participants with disabilities: Implications for counselors." J Counsel Develop 76:311-316.

[25]. Frank Seagraves, Michael Horvat, Christine Franklin, and Karen Jones "Effects of a School-Based Program on Physical Function and Work Productivity in Individuals with Mental Retardation”Clinical Kinesiology v 58 (2); Summer 2004 